\title{
BMJ Open Quality Improving oral health through dental fluoride varnish application in a primary care paediatric practice
}

\author{
Sathyanarayan Sudhanthar, ${ }^{\ominus}$ Jillian Lapinski, Jane Turner, Jonathan Gold, \\ Yakov Sigal, Kripa Thakur, Olga Napolova, Michael Stiffler
}

To cite: Sudhanthar S, Lapinski J, Turner J, et al. Improving oral health through dental fluoride varnish application in a primary care paediatric practice. BMJ Open Quality 2019;8:e000589. doi:10.1136/ bmjoq-2018-000589

- Additional material is published online only. To view please visit the journal online (http://dx.doi.org/10. 1136bmjoq-2018-000589).

Received 27 November 2018 Revised 18 April 2019 Accepted 13 May 2019

Check for updates

(c) Author(s) (or their employer(s)) 2019. Re-use permitted under CC BY-NC. No commercial re-use. See rights and permissions. Published by BMJ.

Pediatrics and Human Development, Michigan State University College of Human Medicine, East Lansing, Michigan, USA

Correspondence to Dr Sathyanarayan Sudhanthar; sudhanth@msu.edu

\section{ABSTRACT}

Dental caries affect $97 \%$ of people during their lifetime. A total of $59 \%$ of children aged 12-19 will have at least one documented cavity. The American Academy of Pediatrics recommends fluoridated toothpaste to all children starting at tooth eruption, regardless of caries risk. Besides, fluoride varnish is recommended for all children every 3-6 months from tooth emergence until they have a permanent dental home. This project aimed to increase oral fluoride varnish application for children starting at 6 months or the time of tooth eruption up to 3 years of age by at least $50 \%$ over 18 months.

The stakeholders identified were physicians, nurses, medical assistants and the health information team. We obtained baseline data about oral health screening and fluoride varnish from both the clinic sites. The quality improvement (QI) project was based on Plan-Do-StudyAct (PDSA) cycles with a 6-month gap in-between the three cycles. For the first cycle, all medical staff members participated in 2-hour knowledge and skills training on dental caries and current recommendations on fluoride varnish. PDSA cycle 2 involved having automatic reminders for providers in electronic medical records. PDSA cycle 3 planned to have automatic fluoride orders for the recommended age groups. The QI team analysed the results after every 6 months, and improvements were made based on the input from data and medical staff. The number of patients who had fluoride varnish applied increased from $14 \%(n=50)$ to $55 \%$ at the end of PDSA cycle 3. Administration of the varnish did not affect the flow of the patients in busy primary care practice. The rate of improvement was across all the age groups, providers and in both clinical sites. It is possible to adhere to the oral fluoride varnish guidelines in a busy primary care practice, which may help benefit young children who are at risk for caries.

\section{PROBLEM}

Dental caries affects $97 \%$ of the world population during their lifetime. At least $59 \%$ of children in the age group of 12-19 years will have one documented cavity. The American Academy of Pediatrics (AAP) recommends fluoridated toothpaste to all children starting at tooth eruption regardless of caries risk. In addition, the academy recommends fluoride varnish for all children every 3-6 months from the age of tooth emergence until they have a permanent dental home. The Michigan State University College of Human Medicine general paediatric clinic is an academic practice serving about 4000 children. The practice serves a diverse population, and about $60 \%$ of the children in it are considered underserved. The practice has eight physicians along with support staff, including nurses and medical assistants. Typically, children in the practice have had difficulty establishing a dental home before 3 years of age. Fluoride varnish every $3-6$ months is an effective method with which to protect the teeth from decay. This is especially true for children of families who face barriers like the inability to establish a dental home. All our patients were regularly administered a screening questionnaire about oral health in which parents had to answer about behaviours such as nighttime bottle or breast feeding, family history of tooth decay, brushing twice daily, regular exposure to sweetened beverages and fluoride availability in the water. On review of these questionnaires, most of our patients had two or more risk factors, which can contribute to poor oral hygiene, and eventually, tooth decay. Most children who had risk factors also belonged to the underserved population who were prone to having barriers to healthcare access. To address the problem, we decided to improve our oral fluoride varnish rates for all children from age 6 months or from tooth emergence until 3 years of age. This project aimed to improve the oral fluoride varnish application rate for children starting at 6 months of age or at the time of tooth eruption up to 3 years of age by at least $50 \%$ over 18 months.

Globally, 2.4 billion adults and 621 million children are affected by caries, which makes dental caries one of the most prevalent chronic conditions for the world population. ${ }^{1}$ Caries or tooth decay has a significant impact on children and their families. In multiple studies, it has been shown that tooth decay 
has a substantial social impact on children concerning their pain, sleep, social activities, eating and school attendance as well as an emotional impact during childhood. ${ }^{2}$ In the USA, the prevalence of caries in children aged $2-19$ is $43 \%$, and the prevalence of untreated caries in the same age group is $13 \%$. Though the gaps in the prevalence of caries and untreated caries and frequency of dental visits due to social determinants are narrowing, there are still some significant differences among race, ethnicity, income and insurance levels. For example, 39\% of non-Hispanic whites have caries compared with 52\% of Hispanic children. Eleven per cent of Asian children have untreated caries compared with $17 \%$ of non-Hispanic African-American children. Only 34\% of children in a household with an income greater than $300 \%$ above the poverty level experience caries as compared with $51.8 \%$ of children with a salary of less than $100 \%$ above the poverty line. ${ }^{34}$

The impact of dental disease on the economy is another factor to consider. In 2010 , the WHO estimated $\$ 6.5$ trillion as of the global health expenditure with dental expenditure amounting to $4.6 \%$ of this estimate ( $\$ 298$ billion). High-income countries including North America and Western Europe contribute $83 \%$ of that estimate. Indirect costs due to productivity loss in 2010 due to dental disease were estimated to be $\$ 144$ billion of which $17 \%$ was due to untreated caries. ${ }^{5}$ Multiple studies have shown the effect of fluoride in preventing and in some cases even reversing caries. Fluoride toothpaste, fluoride gel and fluoride varnish have all been shown to avert caries risk in both permanent and decidual teeth. ${ }^{6-8}$ The American Dental Association (ADA) in its report concluded that $2.26 \%$ of fluoride varnish is recommended for all children under 6 years of age who have high caries risk. ${ }^{9} \mathrm{~A}$ meta-analysis from 2016 showed topical fluoride varnish was effective in preventing emerging caries lesions. ${ }^{10}$

Though most professional organisations, such as the ADA and the American Academy of Pediatric Dentistry, recommend targeting children with high caries risk for fluoride varnish, the AAP recommends the application of fluoride varnish to all infants and children in primary care settings at least every 3-6 months starting from tooth emergence until they have established a dental home. ${ }^{11}$ The AAP also added it as a guideline for well-child visits for primary care physicians. The US Preventive Services Task Force recommends applying fluoride varnish by primary care providers starting at the age of tooth eruption up to 5 years of age. ${ }^{12}$

\section{MEASUREMENT}

To understand the fluoride varnish rates in our academic practice, we collected baseline measurement retrospectively by reviewing clinical encounters of 50 randomly selected patients aged 6 months up to 3 years who had a well-check visit in the past month prior to the implementation of the generalised fluoride varnish for all children. It was found that about $48(96 \%)$ of the baseline population were administered the oral health screening tool to assess their individualised oral risk. All the charts had documentation of the oral health tool being administered (scanned as a patient document). The following parameters were collected to indicate their risk category. Sixteen $(32 \%)$ of the patient families had reported no or occasional access to a dentist. Nineteen of $34(55 \%)$ patients who have a dental home have been diagnosed with dental decay or high risk for caries. A third of the patients had indicated a family history of tooth decay in a sibling or a parent. A quarter of the baseline population families were using night-time feeding with a bottle for the past 12 months of age. Two (4\%) of the baseline population reported no fluoride in their water source. Only 7 of 50 (14\%) baseline population had a record of at least one varnish applied in the office. Of those who had the fluoride applied, only two children had more than one application recorded. For the quality improvement (QI) project, the team decided to concentrate mainly on collecting data on fluoride varnish rates for all children from 6 months or tooth emergence up to 3 years of age because most children above 3 years of age reported having a permanent dental home. Besides, the largest payer in the state for the underserved population only paid for fluoride varnish until 3 years of age.

\section{DESIGN}

In an internal review, the results of the baseline measurement were shared with all practice stakeholders including medical assistants, nurses and physicians. Our practice has always aimed to follow AAP guidelines. It was clear that we would have to make a practice-wide change to improve our oral fluoride varnish rates. Although all providers and nursing staff agreed on the benefits of such an improvement, concerns were raised on the workflow and the time commitment for the implementation of fluoride varnish for all children. The health information team (HIT) was also included as one of our stakeholders and an office workflow template was developed.

The nursing staff was to administer the oral health questionnaire and document the risk factors either in the chart or on the form itself. The nursing staff was also to record if the patients already had a permanent dental home or not. The physicians would review the oral health questionnaire and counsel parents and children on proper oral behaviour and then authorise the fluoride varnish for the appropriate ages. The medical assistants or the nurses would then apply the fluoride varnish along with the immunisations for the children at the end of the visit.

The implementation team met every 6 months to review the fluoride varnish rates. The physician and clinic manager in charge answered questions from the clinical staff about the utility of fluoride varnish, questions about clinic workflow for the varnish application and billing questions for the varnish. 
See online supplementary material for clinic flow protocol.

\section{STRATEGY}

The QI project was based on Plan-Do-Study-Act (PDSA) cycles with a 6-month gap in-between the cycles. We aimed to improve the oral fluoride varnish application rate for all children starting at 6 months of age or at the time of tooth eruption up to 3 years of age by at least $50 \%$ in 18 months.

\section{PDSA cycle 1}

Plan: For the first PDSA cycle, we planned to provide education about caries prevention in young children through oral fluoride varnish and skills training on how to apply the varnish to all the providers.

Implementation: All medical staff (physicians, nurses and medical assistants) attended a 2-hour knowledge and skills training on dental caries and current recommendations on fluoride varnish. This skills training was intended to improve the application rate by raising awareness among the clinical staff about dental caries and a tool to combat the caries risk with the in-office application of the varnish.

Measurement: We measured the fluoride varnish rates of 50 well-child visits between the ages of 6 months and 3 years. The measurement was obtained by reviewing the electronic medical records (EMR) from the wellness check visits. This cycle increased the fluoride varnish rates marginally to $21 \%$.

Modifications: Physicians and staff members still had difficulty implementing the varnish. The transition to a new EMR and the already busy well-child visits were cited as significant barriers. The feedback was to implement an automatic reminder that would help the medical staff remember to administer the varnish.

\section{PDSA cycle 2}

Plan: For the second PDSA cycle, the planning team met with the health information technology (HIT) team to request adding automatic reminders for the medical staff in the EMR.

Implementation: The automatic reminders were added in the assessment and plan chart section of the EMRs for specific well-child visits. Thus, when the medical staff members navigate to that section of the chart, they will have to respond if the varnish was applied or not and give a reason if the varnish was not used.

Measurement: The varnish rates measured for 50 children under the specific age groups after this phase showed moderate improvement compared with cycle 1 at $42 \%$. Physicians appreciated the reminders, though many continued to skip the reminders, as they were busy and frequently saw those reminders only as they were completing the charts after the patients had left.

Modification: The team considered implementing an easy order set along with the reminders to help medical staff remember performing the fluoride varnish in the busy clinic environment.

\section{PDSA cycle 3}

Plan: In our third and last PDSA cycle, we incorporated automatic fluoride varnish orders with the help of the HIT team with the well-child visits for the recommended age groups.

Implementation: Automatic orders during the well checks of specific age groups were combined with the reminders already added in the PDSA cycle 2 . The medical staff would have to see this order during the administration of immunisations.

Measurement: The rate of fluoride varnish after the third cycle reached 55\%. Providers acknowledged that it was easier to administer fluoride varnish as the order for varnish is included in the order set for specific visits, and all they had to do was to sign the orders.

Modification: Since the combination of reminders and automatic orders improved the fluoride varnish rates, the team decided to continue these implementations as well as to continue didactic and skills training for all the medical staff.

\section{RESULTS}

Each PDSA cycle was implemented for 6 months, and the primary outcome was the fluoride varnish rate. During each of the cycles, there was mild to moderate improvement of the varnish rate, and 50 patient charts were analysed individually for the application of fluoride varnish. The project achieved its specific, measurable, achievable, relevant and timebound (SMART) aim in improving the fluoride varnish rate, more specifically from a baseline rate of $14 \%-55 \%, 18$ months after the intervention was implemented. There was a fivefold increase in the varnish rate in PDSA cycle 3 compared with the first change. The application of fluoride did not significantly affect the clinic flow and the number of patients seen by providers, as inferred from the schedules during the time. The rise in the fluoride varnish rate occurred across all providers and at both clinic sites.

See figure 1 for the run chart.

\section{Lessons and limitations}

We achieved more than the targeted aim for the project and, as shown in multiple studies, implemented an effective fluoride varnish programme for busy primary care practice. ${ }^{13-15}$ The practice realised that just administering the oral health questionnaire and discussing it with patients does not improve oral health. It has been shown from the literature that only one in four primary care physicians thinks that fluoride varnish should be administered as a part of regular health visits. Two out of three physicians agreed that the reimbursement for the fluoride is inadequate, and one in five physicians did not want to implement the fluoride programme in their offices. ${ }^{16}$ In another study only, half of the paediatricians surveyed reported they examined the oral cavity of their patients 


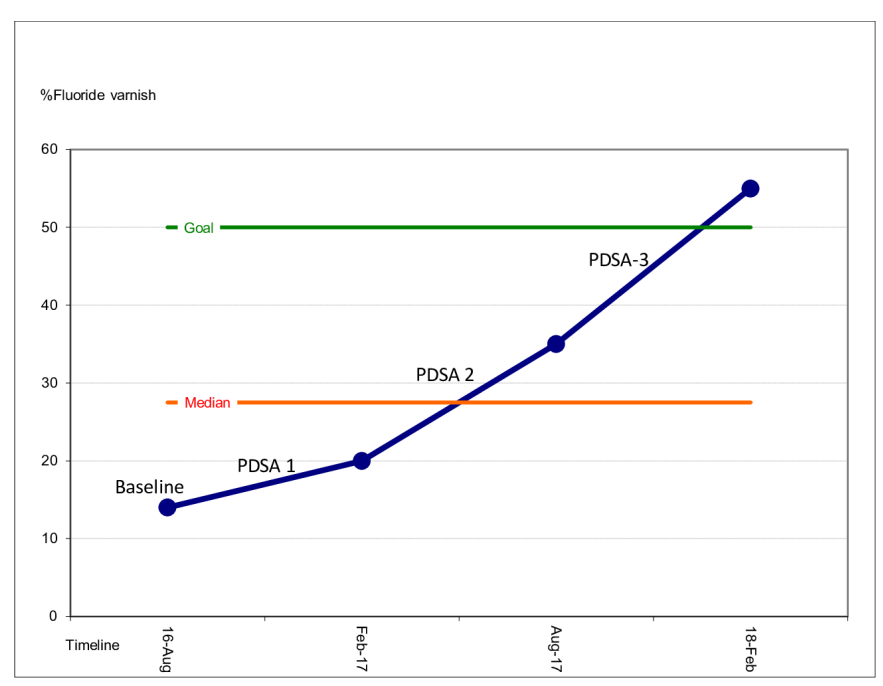

Figure 1 Illustration of run chart documenting the three Plan-Do-Study-Act (PDSA) cycles for the oral fluoride varnish project.

up to age $3 .{ }^{17}$ Lack of training was reported as one of the common barriers by most physicians. ${ }^{18}$

As suggested in the literature, we decided there were three critical factors that led to a positive outcome of the project: (1) understanding the importance of why we need to do it and its impact on the patients (2) communications within the medical staff team notably involving nursing staff and medical assistants in the conversation, and (3) the logistics. ${ }^{18}$ Most physicians understood the importance of the project and the impact it would have on our patient population. As an academic practice that follows the AAP guidelines, all the physician providers were in favour of this project. The perceived barriers were time to administer the varnish, clinic flow, reimbursement and burden on the clinical staff. When the team was included in a standardised state-wide training programme for oral health, most of their perceived fear about the skills necessary to use oral fluoride varnish was discussed and resolved. Some of the other factors that affected the project were the late buy-in from the HIT, transitioning to a new EMR and acquiring funding for fluoride varnish. Parental concern, which was a perceived barrier, did not play a part in the application as none of the parents refused the fluoride application when the staff explained the utility of the procedure. Focus groups of clinic staff reassured the team that the application of varnish itself did not add a huge burden to their clinical work and the mean estimated time for the application was about $60 \mathrm{~s}$. We found that apart from knowledge and skills, addressing the system barriers can play a significant part in the success of a project. When the varnish was added to a standard set of orders, and a clinic flow protocol has developed, the physicians and clinic staff were much more likely to remember to administer the varnish. We think that this project is generalisable to all the primary care physicians who see children from infancy. System barriers may slightly vary, but if these are identified early, the team can make an immediate impact.
Though our project assessed 50 children during the baseline data and for each of the PDSA cycles, not analysing the entire patient population under a specific age group may be a limitation in generalisability.

Even though we were not able to learn if administering oral fluoride varnish prevents early tooth decay to the children in our practice due to the timeline of the project, we have enough data from the literature and academic guidelines to suggest the same.

\section{CONCLUSION}

It is possible to adhere to the oral fluoride varnish guidelines for all children under 3 years of age in busy primary care practice. This will ultimately improve oral health and prevent dental caries, which have considerable impacts on the family and regional, national and global economic burden. The project is being continued, and we have raised our goal of fluoride varnish for the next 12 months to $75 \%$. Administering varnish also stresses the importance of oral hygiene to the parents through discussion with their care provider. The project is sustainable, as the practice can be reimbursed for its effort from all insurances.

Acknowledgements We acknowledge the hard work of all the medical staff of the MSU Child Health clinics including healthcare assistants, medical assistants, nurses and the HIT. Moreover, we thank all our patients with whom we interact daily for their trust in our clinical judgement.

Contributors SS planned the study and created a first draft of the manuscript. $\mathrm{JL}$ conducted the initial baseline data which helped set a target. JT and JG both helped in editing the document and suggesting critical changes. YS, KT, ON and MS all participated in the planning and implementation of various PDSA cycles. All the authors were involved in a 2-hour training for fluoride varnish through the local health department initiative, participated in the daily planning of fluoride varnish administration to all patients and had also reviewed the manuscript.

Funding The authors have not declared a specific grant for this research from any funding agency in the public, commercial or not-for-profit sectors.

Competing interests None declared.

Provenance and peer review Not commissioned; externally peer reviewed.

Open access This is an open access article distributed in accordance with the Creative Commons Attribution Non Commercial (CC BY-NC 4.0) license, which permits others to distribute, remix, adapt, build upon this work non-commercially, and license their derivative works on different terms, provided the original work is properly cited, appropriate credit is given, any changes made indicated, and the use is non-commercial. See: http://creativecommons.org/licenses/by-nc/4.0/.

\section{REFERENCES}

1. Kassebaum NJ, Bernabé E, Dahiya M, et al. Global burden of untreated caries: a systematic review and metaregression. J Dent Res 2015;94:650-8.

2. Gilchrist F, Marshman Z, Deery C, et al. The impact of dental caries on children and young people: what they have to say? Int J Paediatr Dent 2015;25:327-38.

3. Snapshot of America's Children, 2018. Available: http://www.aapd. org/assets/1/7/Childs_Snapshot_2018_web_version.pdf [Accessed 19 Nov 2018].

4. Health, United States, 2017 - data finder. Available: https://www.cdc. gov/nchs/hus/contents2017.htm\#060 [Accessed 19 Nov 2018].

5. Listl S, Galloway J, Mossey PA, et al. Global economic impact of dental diseases. J Dent Res 2015;94:1355-61.

6. Marinho VCC, Worthington HV, Walsh T, et al. Fluoride varnishes for preventing dental caries in children and adolescents. Cochrane Database Syst Rev 2013;40. 
7. Marinho VC, Higgins JP, Sheiham A, et al. Fluoride toothpastes for preventing dental caries in children and adolescents. Cochrane Database Syst Rev 2003;(1).

8. Marinho VCC, Worthington HV, Walsh T, et al. Fluoride gels for preventing dental caries in children and adolescents. Cochrane Database Syst Rev 2015;(6).

9. Weyant RJ, Tracy SL, Anselmo Theresa (Tracy), et al. Topical fluoride for caries prevention. J Am Dent Assoc 2013;144:1279-91.

10. Lenzi TL, Montagner AF, Soares FZM, et al. Are topical fluorides effective for treating incipient carious lesions?: a systematic review and meta-analysis. J Am Dent Assoc 2016;147:84-91.

11. Clark MB, Slayton RL, Section on Oral Health. Fluoride use in caries prevention in the primary care setting. Pediatrics 2014;134:626-33.

12. Final update summary: dental caries in children from birth through age 5 years: screening. U.S. Preventive Services Task Force, 2016. Available: https://www.uspreventiveservicestaskforce.org/Page/ Document/UpdateSummaryFinal/dental-caries-in-children-frombirth-through-age-5-years-screening [Accessed 16 Apr 2019].
13. Biordi DL, Heitzer M, Mundy E, et al. Improving access and provision of preventive oral health care for very young, poor, and low-income children through a new interdisciplinary partnership. Am J Public Health 2015;105 Suppl 2:e23-9.

14. Winter J, Weber K, Martin K, et al. Evaluation of an intensified prevention program for 4th graders with increased caries risk using ICDAS. Int J Paediatr Dent 2016;26:250-8.

15. Gnaedinger EA. Fluoride varnish application, a quality improvement project implemented in a rural pediatric practice. Public Health Nurs 2018;35:534-40.

16. Isong IA, Silk H, Rao SR, et al. Provision of fluoride varnish to Medicaid-enrolled children by physicians: the Massachusetts experience. Health Serv Res 2011;46:1843-62.

17. Lewis CW, Boulter S, Keels MA, et al. Oral health and pediatricians: results of a national survey. Acad Pediatr 2009;9:457-61.

18. Lewis $\mathrm{C}$, Lynch $\mathrm{H}$, Richardson $\mathrm{L}$. Fluoride varnish use in primary care: what do providers think? Pediatrics 2005;115:e69-76. 